\title{
KEY COMPONENTS OF MUSICAL DISCOURSE ANALYSIS
}

\author{
EVGENIYA ALESHINSKAYA \\ Lobachevsky State University, Nizhniy Novgorod, Russia \\ aleshinskaya_jane@yahoo.co.uk
}

\begin{abstract}
Musical discourse analysis is an interdisciplinary study which is incomplete without consideration of relevant social, linguistic, psychological, visual, gestural, ritual, technical, historical and musicological aspects. In the framework of Critical Discourse Analysis, musical discourse can be interpreted as social practice: it refers to specific means of representing specific aspects of the social (musical) sphere. The article introduces a general view of contemporary musical discourse, and analyses genres from the point of 'semiosis', 'social agents', 'social relations', 'social context', and 'text'. These components of musical discourse analysis, in their various aspects and combinations, should help thoroughly examine the context of contemporary musical art, and determine linguistic features specific to different genres of musical discourse.
\end{abstract}

\section{Introduction}

Contemporary musical discourse is of utmost research interest due to the global status of the English language, which has been adopted as a new 'lingua franca' in the sphere of contemporary musical art, operating across national borders and becoming increasingly multicultural and multinational. Musical discourse in all its diversity opens up infinite possibilities for multidimensional analysis combining social, linguistic, psychological, visual, gestural, ritual, technical, historical, and musicological aspects. However, very little attention has so far been paid to discourse analytical investigations of the use and social aspects of the global language in various genres of musical discourse. This article therefore attempts to address the area that has not been investigated in the previous linguistic studies, being focused on such components of musical discourse as semiosis, social agents, social roles, social context and text, and their role in musical discourse analysis, in particular the paper addresses the question of how such aspects can help differentiate between genres of musical discourse.

\section{Musical discourse as an object of linguistic research}

Despite the growing interest in popular music studies and musical discourse analysis, communication in the sphere of musical art has not been subject to a complex linguistic analysis. The analysis of discourse has been applied in three ways to popular music: in the study of song lyrics as performed language, in the description of discourses on or about music, and in the analysis of music as discourse (Bradby 2003: 67). As a result, 
there is no universal definition, and even no universal variant of the term itself: it is either 'musical discourse' (Tagg 2003) or 'music discourse' (Moore 2001), 'song discourse' (Murphey 1992), 'discourse of music' or 'discourse about music' (Blacking 1982).

However, it is commonly accepted that musical discourse cannot be reduced to the music itself (Roy 2010: 15). Different scholars suggest including various extramusical aspects in musical discourse analysis, such as psychological, personal factors, social and historical environment, stylistic conventions, artistic aims and so forth (Blacking 1982; Morgan 1982; De Nora 2000; Roy 2010). In conclusion studying musical discourse is, with no doubt, an interdisciplinary matter: it cannot be complete without consideration of social, linguistic, psychological, visual, gestural, ritual, technical, historical and musicological aspects (Tagg 2003: 74).

According to Pavlovová (2013), the specific language of musical discourse still remains on the periphery of interest of discourse analysts. The complex linguistic analysis accurately described in her book deals with the genre of concert notice, and is conducted from the perspective of text type, providing a detailed account of phenomena peculiar to noun and verb phrases, as well as lexical and stylistic aspects of the genre, and how the language itself is employed by expert genre writers in order to achieve their communicative intentions.

In my research the aim is not to focus on one particular genre of musical discourse, instead, I intend to outline the area of musical discourse in general and show its diversity in various genres, relating them to different stages of 'life' that musical products can "live". The work analyses sociolinguistic features typical of seven genres (song lyrics, live performances, musical interviews and reviews, Internet forums, academic publications, and jam sessions), which are relatively easy to access via mass media. Recent works on discourse analysis (Fairclough 2003, 2006), and genre theory (Bhatia 2004, 2008) helped shape the framework for the analysis of sociolinguistic peculiarities of contemporary musical discourse.

\subsection{Musical discourse and critical discourse analysis}

My approach to musical discourse analysis is based upon a version of Critical Discourse Analysis developed by Fairclough (2003, 2006). Fairclough (2003) distinguishes three levels of abstraction within social analysis: social structures, social practices and social events. Social practices are "the way things are generally done or happen in particular areas of social life", and are associated with particular institutions and organizations. Texts can be interpreted then as "the discourse moments of social events". In social practice, discourse figures in three main ways: as genres (particular ways of acting communicatively), discourses (particular ways of representing some aspects or areas of social life), and styles (the discourse moments of a social or personal identity) (Fairclough 2006). Discourse is used in two senses: (1) as an abstract noun, meaning language and other types of semiosis as elements of social life, and (2) as a count noun, meaning particular ways of representing aspects of social life. Discourse in the first sense will be hereafter referred to as semiosis, and it is the semiotic aspect of social 
processes, including verbal language and nonverbal language (visual images, body language etc.).

Musical discourse as social practice can be therefore defined as a category referring to specific means of representing specific aspects of musical life. Such a wide understanding allows bringing together various directions in musical discourse analysis: music as discourse (Agawu 2009; Sawyer 2005; Walser 1993); song (lyrics) discourse (Dunyasheva 2010; Murphey 1992); critical discourse, or discourse about music (De Nora 2000; Morgan 1982); and a total of utterances thematically related to music (Mudryan 2011).

\subsection{Musical discourse and genre theory}

Genre analysis is generally understood to represent "the study of linguistic behavior in institutionalized academic and professional settings", as linguists concentrate on a dynamic explanation of the ways in which professionals (or professional users of language) "manipulate generic conventions to achieve a variety of complex goals associated with their specialist disciplines" (Bhatia 1997: 313-314). Being reflections of professional cultures, genres focus on social actions "embedded within disciplinary, professional and other institutional practices" (Bhatia 2004: 23). Thus genre analysis combines elements not only from linguistics, but also from sociolinguistics, ethnographic studies, psycholinguistics and cognitive psychology, communication theory, studies of disciplinary cultures, and insights from professional language users. 'Professional' here is not related to the level of knowledge of the language, as a perfect knowledge of the language is not necessary or sufficient to communicative expertise (Bhatia 1997). It is rather synonym to 'paid-work related', and covers both skilled and unskilled paid jobs in a particular discipline or field (Gunnarsson 2009: 5), which in the case of musical discourse is the music industry.

With regard to musical discourse, genre can be understood as a type of text (discursive genre) and a type of music (musical genre). Discursive genres are particular ways of communicating, using language associated with a particular social activity (Fairclough 2006), and they act as means of organizing and formalizing social interaction in the sphere of contemporary musical art. Moreover, a discursive genre may have various features depending on the musical genre communicants affiliate themselves with, which deserves a more thoughtful investigation in its own right.

In accordance with the recent tendency in genre theory to shift emphasis from text to context, Bhatia $(2004,2008)$ offers a multi-perspective model of discourse comprising three views on discourse (as text, genre, professional practice or social practice), which are interacting and essentially complimentary to each other. This generic perspective on discourse analysis looks at discourse as genre and takes into account both textual features (textualization of specific features of lexico-grammar, and textual organization), and certain features of social practices, especially those related to professional practices. In a certain sense my work is continuation of Bhatia's genre-based view of discourse, arguing that such components of discourse as semiosis, social context, social agents, social roles and text with their specific features can help integrate textual and contextual analysis, as well as distinguish among genres of musical discourse. The basic analytical 
framework, employing the theory of critical discourse analysis and genre theory, proves to fit with multi-perspective and multidimensional analysis of various genres of musical discourse.

\section{Data and method}

Discourse analysis implies examination of texts in a wide sense - both written and spoken, as well as complex multimodal texts of television and the Internet, where language is used in combination with other semiotic forms (Fairclough 2006: 25-26). In order to illustrate musical discourse in all its diversity by reflecting processes at different stages of 'life' of musical products and their social contexts, materials for the present research were drawn from musical journals ("Billboard", "Downbeat", "Rolling Stone", "American music", "Blender", "Bullz eye", "NME", "Interviews"); sound recordings of musical interviews (http://www.toazted.com/interview, 79 minutes); sound recordings of musical radio programs on BBC Radio Two (http://www.bbc.co.uk/programmes /b006wr34/episodes/player, 600 minutes); television interviews on VH1, BBC World and from http://www.youtube.com (518 minutes); video recordings of live performances, musical rehearsals, studio sessions and jam sessions on http://www.youtube.com (890 minutes); audio and video materials of live performances by "Ghosts", "Keane" (London, 21.07.2007), "Stereophonics" (Swansea, 26.07.2007), "The Manic Street Preachers" (Moscow, 23.07.2008), "Keane" (Moscow, 27.09.2009), and music festivals "The Admiral Cardiff Big Weekend" (Cardiff, 3-5.08.2007), "V Festival" (Weston Park, Staffordshire, 16-17.08.2008); musical Internet forums (http://forums.myspace.com, http://8notes.com/f/, http://www. acousticguitarforum.com, http://forums.allaboutjazz .com/). Lyrics of 129 songs belonging to pop (45), rock/hard rock (46) and rap music (38) were selected by referring to the top musical categories from the Billboard charts (January - June 2013) on www.billboard.com, and then collected, using the search engine www.google.com. The sites most frequently used for lyrics in this study included azlyrics.com, and lyrics007.com.

My aim was to distinguish types of lexical units and semantic structures peculiar to different genres of musical discourse and explain their use from the point of view of the social context; thus I decided to employ qualitative social analysis. I examined textual features (sentence structure, lexical choice) within a critical perspective and "the contextual frame" of the production of discourses (Baxter 2010: 128) in order to answer the question: 'Why do social agents in the music industry use the language the way they do?' (Bhatia 2008). A special focus was on the status of specialized language units extracted from authentic texts. It was verified with the help of dictionaries of specialized language lexemes (Hitchcock \& Sadie 2002; Kernfeld 2003; Latham 2002) and online musical dictionaries and encyclopedias (http://www.grovemusic.com, http:// www.solomonsmusic .net, http://www.allmusic.com). Interpretation of the social context was facilitated by the analysis of academic books and articles devoted to the cultural aspects of different musical genres and specific types of interaction in musical discourse, some of which were included in the reference list. 


\section{General view of musical discourse}

Data examination and interpretation allows drawing the general view of musical discourse, which can be represented schematically in a form of an ellipse illustrating the main four stages of 'life' of a musical product, including its creation, distribution, and perception (see Figure 1). The 'creation of the musical product' stage comprises elements such as jam sessions, musical rehearsals, studio sessions, shooting a music video etc. The 'completed musical product' stage is represented by song lyrics, scores, tablatures, music CD/DVDs, EP/LPs, music videos etc. The 'distribution of the musical product' includes live performances, TV/radio broadcast of live performances, musical interviews, musical articles, album presentations, musical ceremonies, concert/tour notices, press releases, charts, CD/DVD sales etc. And the 'perception and evaluation of the musical product' stage embraces musical reviews, general Internet forums and chats.



Figure 1: General view of musical discourse 
To the main four stages of 'life' of a musical product illustrated in Figure 1, I have added the 'description/reflection' aspect of a musical product, which is represented by educational discourse, academic discourse, fiction, in other words films/books/biographies, musical quizzes, lessons and workshops, TV/radio (educational) programs, textbooks, dictionaries, encyclopedias etc., and finally by professional Internet forums; and 'records management' comprising negotiations, contracts, correspondence, riders, and other aspects of musical business discourse. They can enter musical discourse at any of the four main stages. For example, musical educational discourse includes teaching elements of composition and sound recording ('creation of a musical product'), teaching how to perform musical pieces ('distribution of a musical product'), and teaching basics of musicological analysis ('completed musical product', 'perception/evaluation of a musical product').

\section{Components of musical discourse and their role in discourse analysis}

The key components of musical discourse as social practice are 'semiosis', 'social agents', 'social relations', 'social context' and 'text'. They are all interconnected and essential in musical discourse analysis: depending on the social context, social agents, who are in specific social relations, employ specific semiosis and produce a text, which is associated with a particular social context. Each component can be analyzed from different angles, thus creating a detailed picture of different genres of musical discourse.

\subsection{Social context}

Social context determines the way in which social agents, who are in certain social relations, communicate with each other and what language (semiosis) they use. The notion of social context in the sphere of modern musical art is very wide: it can be a place, time of communication, social factors and so forth. Social context is of great research interest from the point of view of the activity, communicative technology, level of formality, situation type, place of communication, and normative expectations.

The communicative purpose is considered to be "a crucial genre determinant" (Bhatia 1993: 13), as it influences the content, shapes the structure and determines the linguistic features of various genres within musical discourse (Pavlovová 2013: 7). Following Fairclough, the communicative purpose in this work is referred to as the activity (or purpose of activity), an adapted version of the communicative purpose, which is better formulated in a question "What are people doing discoursally?" (Fairclough 2003: 72). For instance, jam sessions occupy a space somewhere "between a formal public performance and a private after-hours music-making of consociates" (Doffman 2011: 22). The purpose of jazz improvisation is not to generate "a created product that will then be displayed or sold in another context; there is no goal external to improvisation" (Sawyer 2003: 5). In improvisational creativity, the process itself is the goal. Musicians play nonstop, simultaneously listen to other band members and immediately respond to what they are playing. In this way musicians practice, develop 
new materials, find suitable arrangements for their compositions, as well as exchange musical ideas and test their improvisational skills.

Discourse, and musical discourse in particular, can be further differentiated with respect to communication technologies in terms of two-way/one-way communication, and mediated/non-mediated communication (Fairclough 2003: 77). This gives us four possibilities: two-way non-mediated (face-to-face communication), two-way mediated (telephone, email, video conferencing), one-way non-mediated (lecture), one-way mediated (print, radio, television, Internet, film). If a studio session is characterized by two-way non-mediated communication, then the result of studio recording (a completed musical product, for instance, a track on a CD) is usually one-way mediated.

The level of formality is also essential in defining genres of musical discourse, suggesting formality or informality of communication within a particular genre, which to a great extent conditions the use of specific lexemes and syntactic structures, and is related to the place of communication and the situation type. The situation type is represented by either institutional or everyday (routine) situations, depending on the place of communication. Examples of institutional situations are live performances at arenas and concert halls, studio sessions in studios, music classes at music schools or colleges etc. By contrast, everyday situations, like listening to radio programs, watching live shows online/on television/on DVD, chatting or reading musical interviews in a journal, are not limited by musical institutions. The place of communication in general (i.e., a country or a town) sometimes also affects the language used in a conversation: in order to please the local public musicians usually employ some high-frequency words in the local language such as 'hello', 'thank you', 'good evening', 'goodbye', or names of some phenomena of the local culture (cuisine, music, clothing, architecture, literature etc.). Thus, during concert performances in Moscow or in musical interviews for Russian radio stations, journals or television channels, foreign musicians usually insert some Russian words or phrases they know or came to know while staying in the country, and these are typically privet (hello), kak dela (how are you), spasibo (thank you), devushki (girls).

To some degree, social agents are controlled by social expectations and norms. For instance, in live performances (pop/rock/heavy metal/jazz/hip hop concerts or festivals etc.), although typically characterized by formal setting, it is quite normal to expect audiences to dance, sing, or interact with the performers in other ways. Musical genres can also determine the normative expectations in some discursive genres, especially those relating to one musical genre (rap battles or public jams in jazz cafes). Thus, participants of a jam session share a set of social conventions, the so-called 'etiquette' of improvisation (Becker 2000), learned through a process of professional socialization. These conventions in practice come down to the following statements: (1) all musicians should have the freedom to express themselves; (2) players are mutually interdependent and should limit their individual freedom for the good of the group (Berliner 1994: 417).

\subsection{Social agents}

Different social contexts condition various combinations of social agents. First of all, social agents or communicants in musical discourse perform various social roles: they 
can be musicians, vocalists, managers, producers, conductors, coaches, sound technicians, concert promoters, record manufacturers, staff at retail music stores, music critics and journalists, musicologists, radio DJs and VJs on music channels, and many other representatives of modern music industry, including consumers of musical products. Thus, studio sessions generally involve musicians, session musicians, vocalists, back vocalists, producers; musical interviews involve musicians/producers/vocalists etc., journalists and audience; and professional forums attract a wide range of social agents from musicians, vocalists, sound engineers to musicologists, coaches, producers, and so forth.

In addition to the social roles they perform in various social contexts, social agents may differ in their levels of expertise (Bowker \& Pearson 2002: 27-28), thus being professionals, semi-professionals or non-professionals. Therefore we can talk about three levels of communication within musical discourse, which condition different use of semiosis, in particular different proportions of specialized language and general language lexemes, within different genres of musical discourse. Communication between professionals is usually characterized by a high proportion of specialized lexemes, while communication between professionals and semi-professionals is marked by a considerably lower proportion of specialized vocabulary. In the case of 'professional - non-professional' communication, professionals use general language words to give simplified descriptions of a specialized concept.

Thus, professional Internet forums represent the 'professional-professional' type of communication, where experts share a common background, special knowledge and specialized language. Musical journals, for example, combine musical interviews (distribution of musical products) and musical reviews (perception and evaluation) and belong to the 'professional-semi-professional' type, where semi-experts may be familiar with some of the terms and concepts in question. Song lyrics or live performances represent musical products and their distribution, and belong to the 'professional-nonprofessional' type of communication, being addressed to a wide audience with a low level of expertise.

\subsection{Social relations}

Social relations may be either symmetrical (horizontal) or asymmetrical (vertical). In musical discourse, due to dominant informal setting, long cooperation, very often close connections in life, symmetrical relations prevail, in other words roles performed by communicants are equal. However in each group there is a leader who holds a higher position. Or musicians may position themselves higher in relation to, for example, stagehands or sound engineers. In this case communication is based on asymmetrical relations, that is one of the communicants performs a leading, dominant role.

Horizontal relations are peculiar, for example, to jam sessions and professional Internet forums, while vertical relations are typical of musical reviews and academic publications. Social relations in musical discourse may have a more complicated structure. For instance, a studio session is characterized by symmetrical relations between band members, and asymmetrical relations, on the one hand, between band members and session musicians, and on the other, between a sound producer and 
musicians. Besides, the band leader may position himself higher than his fellow musicians.

\subsection{Text}

Various discursive genres are characterized by different types of texts. Text is a product of social activity, a result of interaction of social practices and social agents. According to Fairclough (2003: 21), some social events, like lectures or interviews, may have a highly textual character, while others may not: although a football match does contain talk (for example, a player calling for the ball), "it is a relatively marginal element, and most of the action is non-linguistic".

In relation to musical discourse, I differentiate between the main two types of texts: 'texts' and 'musical texts'. Verbal texts relating to music appear in various types of sources: journals, websites, interview records, contracts, riders etc. They can be written or spoken. Musical texts include different kinds of notation, tablature, CDs/DVDs, tracks, singles etc. Musical texts can be written (scores, notation, tablature) or performed (tracks/songs played at a concert or recorded on a CD/DVD etc.). For instance, in the course of improvisation (mostly in jam sessions) social agents produce mainly musical texts, and to a lesser extent verbal texts, and none of them are written, due to the focus on the process of improvisation itself.

Types of texts can also be distinguished basing on their structure. In order to communicate their intention, social agents follow specific conventions when they organize messages/texts, and these specific patterns constitute recognizable genres. For example, Pavlovová (2013: 19) describes the basic organization of a typical concert notice in the following sequence: (1) date, time; (2) venue; (3) headline - optional; (4) featuring performers; (5) featuring compositions; (6) performers' achievements/qualities of work; (7) quotations from reviews - optional; (8) price, running time, sponsors.

Public jam sessions usually consist of musical and verbal parts. First of all, they have a well-defined musical format (open-mic, showcase or open circle etc.), which is controlled by a moderator and announced prior to the event. The musical part of the performance begins with the song's melody so that the audience can recognize the song, and then the musicians quickly progresses to a series of solo improvisations (Sawyer 2003: 31). However, before the musical improvisation begins, the social agents usually have a limited verbal discussion of the chord sequence, the tempo, and who will play the head of the tune (Doffman 2011: 214). In the end the social agents might evaluate each other's participation and discuss possibilities of further cooperation.

\subsection{Semiosis}

Verbal language. Musical discourse is attractive for linguistic research due to the global character of the English language in contemporary musical art. One should note that there are two languages functioning as universal mediums of communication in the musical sphere. Since the 1590s, Italian opera has been dominant in classical music, thus making Italian the global language of classical music. It is common knowledge that 
classical terms, especially those referring to vocal techniques, are for the most part Italian. The rise of jazz, blues, rock'n'roll, rock, heavy metal, hip hop in addition to the vast development of information and media technologies brought about a new 'lingua franca' of music. David Crystal emphasizes "the dominance of English in the popular music scene today" and states that many people make their first contact with English through Anglo-American popular music (Crystal 2003: 101). But when we speak about English as a dominant medium of communication in musical contexts, we definitely mean not the "abstract Language" but "specific speech forms, genres, styles, and forms of literacy practice" (Blommaert 2003: 608). Musical terms, jargonisms, and values from the sphere of contemporary musical art are in abundance on television, radio and in journals; song lyrics, musicians' biographies and interviews are all easily found on the Internet. In this respect, contemporary musical discourse serves as a powerful tool that globally spreads the English language together with British and American cultures.

The rise of English as a new 'lingua franca' of music however does not automatically exclude the use of Italian. On the contrary, jazzmen, rockers, metal heads still employ such words as legato, arpeggio, staccato, crescendo. But very often English-language musical terms, being more concise and detailed, specify classical terminology. For instance, glissando is used loosely to mean any slide in pitch up or down to or from a fixed note, or between two fixed notes. However, in jazz different types of gliss are distinguished according to directions, speed, and in some cases method of production: doit (a gliss rising from the end of a note), drop/fall off/spill (a gliss falling from the end of a note), lip (a gliss rising to the beginning or falling from the end of a note, on wind instruments achieved without changes in fingering), plop (a rapid gliss falling to the beginning of a note) etc. (Kernfeld 2003: 433-434).

Clipping is a rather frequent way of word-building in English-language musical terminology (for instance, mic for microphone, amp for amplifier etc.). In jazz and rock music classical Italian terms follow the same word-building pattern and, being used in their shortened (clipped) forms, they acquire a more 'English' look: cf. gliss and glissando, arp and arpeggio, cresc and crescendo. And what is more, gliss can be replaced with slide, which indicates contemporary musicians' aiming at their open resistance to classical music. Thus it is possible to conclude that in today's popular music English acts as a predominant means of communication among social agents in the music industry, while the Italian language has been pushed to the sidelines.

In this study I am particularly interested in the way social agents, related to the music industry, make use of language resources to achieve different goals associated with their professions in various professional contexts. For this purpose I have chosen seven genres, which are rather easy to access via the Internet or in various written sources like musical journals, dictionaries, and books on different aspects of music and musical genres. These are song lyrics, live performances, musical interviews, musical reviews, jam sessions, professional Internet forums and academic publications. They are analyzed from the point of view of syntax and vocabulary, with a particular focus on the correlation of specialized language words, which is further defined as one of the genre distinguishing criteria.

The analysis of linguistic features at the level of syntax and vocabulary may reveal specific characteristics typical of different genres of musical discourse. Thus, types of sentence structures vary from complicated in academic publications to simplified 
structures in informal face-to-face or online communication. At the lexical level musical discourse comprises various types of lexical units, such as general language words (including colloquialisms and general slang), and specialized language words, which are represented by (1) musical terms (dragadiddle - drum rudiment, oi! - genre of punk music, growl, umpateedle - techniques of playing wind and brass instruments etc.), and (2) specialized units that are equivalent to terms and have an expressed connotative component in their semantic structure: professionalisms ( $g$ ig - a live performance by a musician or group, go out - end or play a final chorus, up - fast etc.), and jargonisms (ivory tickler - pianist, shiny back - sideman, eggo - CD, wheels of steel - turntables etc.).

The use of general or specialized language words correlates with different levels of communication conditioned by social agents' levels of expertise - professional, semiprofessional and non-professional. This can be illustrated by the examples of jam sessions, professional Internet forums, and academic publications ('professional professional' type of communication); musical reviews, and musical interviews ('professional - semi-professional' type of communication); song lyrics, and live performances ('professional - non-professional' communication) (see Figure 2).

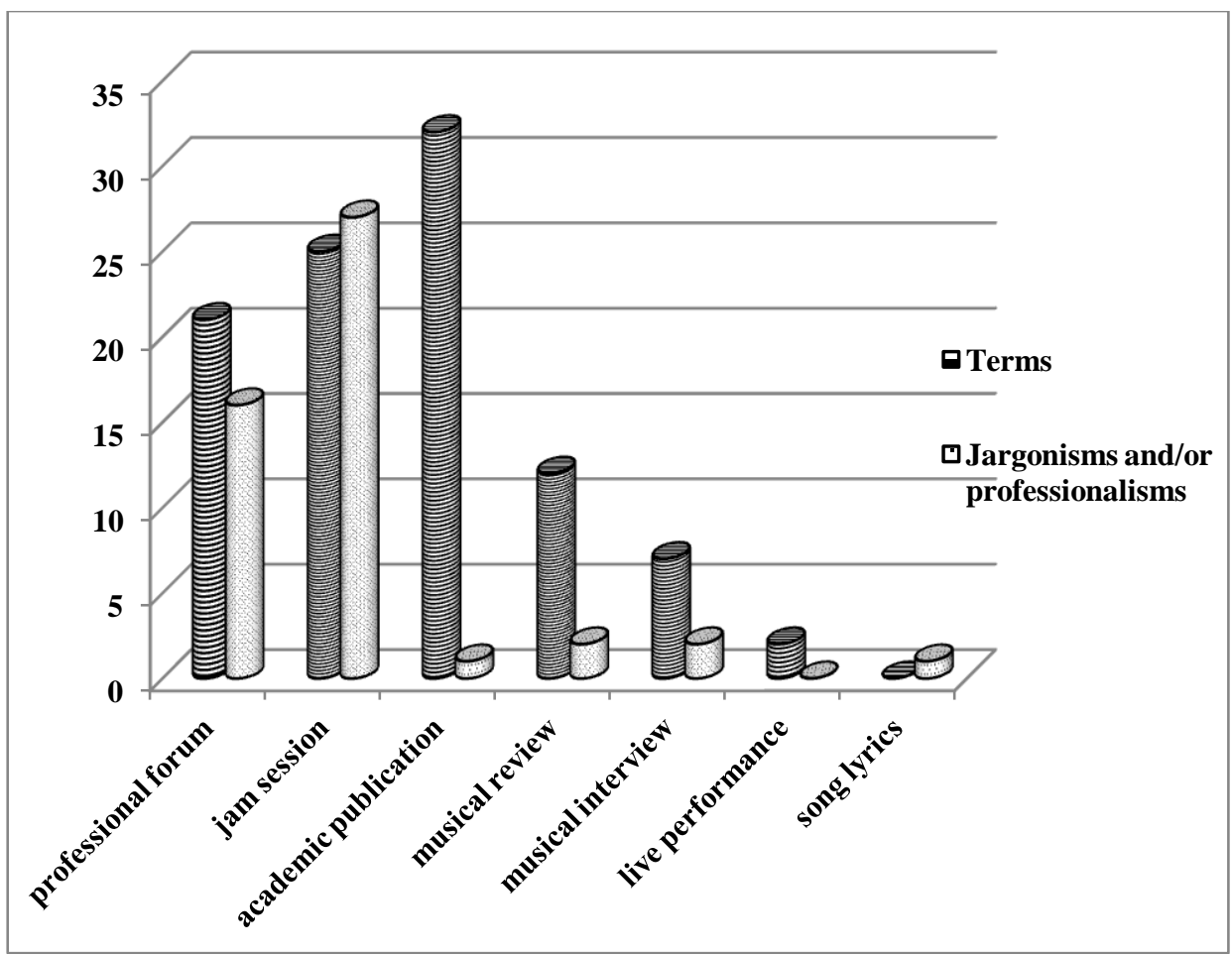

Figure 2: Correlation of specialized language lexemes in musical discourse genres (\%)

Figure 2 illustrates the tendency in live performances to avoid specialized language lexemes due to their focus on a wide audience with superficial knowledge of musical 
subtleties. Song lyrics are typically characterized by the lack of specialized language lexemes due to their general-topic content, not related to the professional side of musical life (with the exception of hip hop song lyrics sometimes containing hip hop jargon). On the other hand, in the discourses of musical reviews, professional Internet forums, jam sessions and academic publications, specialized language lexemes prevail. However, depending on pragmatic factors, the intensity of their use is not the same. Academic publications and live performances do not usually contain professionalisms or jargonisms, although academic publications comprise a much wider range of musical terminology. Musical interviews, musical reviews, and professional forums differ in number and proportions of specialized language lexemes, although terms always constitute a majority. Yet in jam sessions musical jargonisms and professionalisms slightly dominate over musical terminology. Now let us have a look at these genres of musical discourse in detail.

Song lyrics. Song lyrics are a completed musical product, and represent the 'professional - non-professional' type of communication. Song lyrics, especially in pop music and hip hop, have already been thoroughly examined and widely discussed in regard to their pedagogic value (Murphey 1990, 1992), psychological characteristics (Pettijohn \& Sacco 2009; DeWall, Pond, Campbell \& Twenge 2011), stylistic variation of pop song lyrics (Kreyer \& Mukherjee 2009), gender (Bradby 1990; Dunyasheva 2010), and 'glocal' identity construction (Alim, Ibrahim \& Pennycook 2009; Terkourafi 2010; Pennycook 2010).

The qualitative analysis of 129 pop, rock and rap song lyrics from the Billboard charts identified their main tendency to avoid specialized language vocabulary due to their general-topic, non-professional content. However rap lyrics do contain instances of hip hop jargon, or to be more correct, the language 'style' associated with hip hop and rooted in African American English (AAE) communicative practices (Cutler 2007): for example, nigga (friend, buddy), bitch (girlfriend or lover), and $K$ (AK-47 or the number 1000 referring to a monetary figure) in Ace Hood's "Bugatti" ("OK, niggas be hating I'm rich as a bitch / One hundred $K$ I spent that on my wrist"); or hella (really, very, a lot), and dough (money) in Macklemore's "Thrift Shop" ("That shirt's hella dough / And having the same one as six other people in this club is a hella don't"). Alongside with AAE vocabulary, rappers make intensive use of grammatical features of AAE, such as (1) copula deletion, (2) third-person-'s' deletion, (3) multiple negation, and (4) a complex aspectual system, illustrated below by the examples from Kanye West's "Clique":

(1) a. They_kneeling when I_ walking in the building.

b. My girl_a superstar all from a home movie.

c. Every time I'm in Vegas they_screaming like he's Elvis.

d. That if have you look in my life I guess he _talking back.

(2) a. That's Tom Cruise, whatever she accuse.

b. Young player from the D that's killin' everything that he see.

c. Least that what my neck say, least that what my check say.

(3) Ain't nothin' nobody can do with me.

(4) a. I been up straight for nine days.

b. Freaky women I be feelin' from the bank accounts I'm fillin' (Kanye West, "Clique"). 
Ibrahim (1999) distinguishes Black Stylized English (BSE), which banks on ritual expressions habitually and recurrently performed in hip hop, such as bro, flow, nigga, whassup (what is happening), and yo, you homeboy (very cool and close friend). These rituals are more "an expression of politics, moments of identification, and desire than they are of language or of mastering the language per se. It is a way of saying, 'I too am Black' or 'I too desire and identify with Blackness"' (Ibrahim 1999: 351). The main message of hip hop is protest against the reality rappers are living in, and using AAE (or BSE) in hip hop lyrics is a matter of their social identity construction (Cutler 2007; Alim, Ibrahim \& Pennycook 2009).

Live performances. Live performances represent the 'distribution of the musical product' stage and the 'professional - non-professional' type of communication. There are several types of live performances, such as live concerts, television performances where in some part of the show musicians can talk about their music and answer questions of the audience ("Live Session" on MTV, "Unplugged" and "Storytellers" on VH1), and music festivals involving many participants sometimes even at different locations (several stages).

When talking to the audience at a live performance, musicians rarely use terms and specialized language per se, relating to different aspects of musical life. By contrast, thematically colored stylistically neutral lexemes such as album, song, ballad and record are usually employed. Such poverty, or sameness in terminological use indicates deliberate simplification of musicians' speech in order to be understood by a wide nonprofessional audience. For example, Tom Chaplin, the frontman of an English indie-rock band "Keane", introduced the song "Bedshaped" at London O2 Arena (2007), using only note, song and melody:

Are you ready for taking up one more note this evening? For this next song we need every single person in this room. And we don't care if you don't know the song, you don't know the words, the music. We don't care if you can't sing the melody, it doesn't matter. Please, please, just help us. And take a deep, deep breath and sing this next song as loudly as you can. All right?

Musical interviews. Musical interviews represent the 'distribution of the musical product' stage and the 'professional - semi-professional' type of communication, being aimed at both general, non-professional public and the audience with some (superficial or medium) knowledge of musical details (devoted music fans, would-be musicians etc.). Musicians' speech tends towards colloquial style, however alongside with colloquial and general language lexemes, musicians sometimes employ specialized language units. But what is more important, they try not to go too deep into detail and thus avoid sophisticated terminology, choosing simple musical terms and thematically colored lexemes (song, album, ballad, record, hit, band, to play music, to play guitar) like in the following interview with a New York based avant-garde multi-instrumentalist band "GOASTT" (Interview Magazine):

The album came about because we had been making an electric record with a full band, and all our friends who had heard our first song said before we put out a fully electric record we should put out an acoustic record to capture the way the band started, just Charlotte and I in her bedroom writing songs and playing guitar. So before we evolved 
into a fully realized rock band, we decided to just capture the birth of the band and do an acoustic album.

On the other hand, when describing musical processes musicians do employ terms and professionalisms like in time and off time, in tune and off tune etc., but their meanings are familiar to a wide public due to mass media, or rather evident from the general context:

"We recorded everything quite politely, everything was perfectly in time and perfectly in tune"; "I think we were quite surprised having been on the road and rocking out a gig after gig"; "There are mistakes on the record, there are things that are off tune, you know, things that are off time but it, I think, sounds better for it" (Bullz-eye 2006).

In interviews, musicians often depart from standard literary norms and tend towards usual spoken literary norms, which they have a good command of and use in everyday situations. For instance, to the question "Could you be any more sick of the lazy comparisons to Coldplay?", Richard Hughes (a drummer of a rock-band "Keane") answers using sub-standard vocabulary:

Ah, it's just nice having another record out. Hopes and Fears was one part of Keane, and this new record is showing another side to us. I dunno, it's always inevitable. I have a copy of an old magazine called Vox, the monthly NME thing, and the cover of it says, "Radiohead: The New U2?" Y'know? So fuck comparisons (Bullz-eye 2006).

Musical reviews. Musical reviews represent the 'evaluation of the musical product' stage and the 'professional - semi-professional' type of communication. As the target audience is for the most part consumers of musical products, without professional knowledge of musical details and special terminology, the majority of lexemes in musical reviews are those of general language vocabulary. However, as distinct from musical interviews, musical reviews contain a more diverse specialized language vocabulary:

(1) Opener 'Things We Be' emphasises this, kicked off by a simple drumbeat and guitar arpeggio, vocals following seconds later. It has all the urgency of a live show, as does gnarled and dog-eared second track 'I've Got A River' (Welch 2013).

(2) With every Calvin Harris collab attributed to a former grime $M C$, the scene floundered, and the promise of this complex new sound ... was sidelined in favour of making quick bucks with pop hooks (Hoban 2013).

One of the main ways of attracting non-professional and semi-professional readers to musical reviews is their style, which is a combination of journalistic, academic, and colloquial styles. And authors of musical reviews practice a tactics of creating unofficial communicative situations by using expressive colloquial structures and replacing 'dull' terms with emotional jargon and slang words (see collab and pop hooks in the previous example). At the syntactic level this type of discourse contains both simple and complex, expanded sentences with an abundance of secondary syntactic constructions: 
For months now, Queen B has been parading her intentions as regards dominion over our sceptred isle: I own you. Bow down, bitches. It's a done deal before she even issues a royal command...

The pretentious interlude films don't help, Bey intoning 'empowering' yet sorta weak cobblers like: "When you become a woman, you celebrate who you are, and know that sensuality is a gift..." Right now Beyoncé, I wish I could use it to get you to shut up and play 'Single Ladies...' again. Still, even when she's talking guff, she's captivating (Mackay 2013).

In the extract above the author uses several linguistic tactics to describe Beyoncé's show in London. Firstly, the singer is referred to 'royalty' by using thematically related words such as royal, queen, dominion, sceptred. However she is not a queen, she is Queen B, which can be read as Queen Bee, or more likely, Queen of bitches. Bitches, or mere mortal listeners are ranged in a different class, who worship the queen despite her 'talking guff'. However bitch has a positive connotation in AAE, hence in hip hop language, and it is not a secret that Beyoncé (Bey) is an R'n'B, soul, pop and hip hop artist. The author marks herself as one of the 'bitches' class by using colloquial speech words and expressions like shut up, sorta, and talk guff that add familiarity and minimize the distance between the author and the reader.

Jam sessions. Jam sessions represent the 'creation of the musical product' stage and the 'professional - professional' type of communication. Verbal elements in jam sessions are represented mostly be terminological units, on the one hand, and "subneutral" (Skrebnev 1994) specialized units (jargonisms and professionalisms), on the other. Among the most frequent jazz jargonisms are cat (musician), axe (musical instrument), horn (wind or brass instrument), to blow (to play a musical instrument), to swing (to play well).

As for their syntactic structure, jam sessions are characterized by simple sentences typical of colloquial speech. Jam sessions, due to their informal setting and friendly emotional atmosphere, abound in interjections ("Oh!”, “Ah!”, "Yeah!”, “Wow!"), exclamatory statements full of instances of professional jargon: "Everything's jake!" (great), "You're a monster!" (great player), "That is so bad!" (very good), "This cat can sure swing!" (This musician can play well) etc. Besides, jam sessions, especially in limited verbal discussions before musical improvisation begins, contain a lot of nominative sentences like "The head $-A-E-G-D$ minor", as well as imperatives ("Bring your axe”, "Blow your horn!", "Be smellin' yourself” etc.).

Professional Internet forums. Professional Internet forums represent the 'description/reflection' stage and the 'professional - professional' type of communication, and are characterized by a high proportion of specialized language vocabulary and syntactic structures typical of online communication, like in the following example from http://www.acousticguitarforum.com: "On my 12 string the tone pots are push pull and switch the humbuckers to single coil. Very easy to use and $100 \%$ stock. The guitar is a Schecter Stargazer 12 string electric. Gets the ric chime as well or better than my ric." In this fragment most of the specialized vocabulary is thematically related to the technical side of music production, i.e. musical equipment, thus making it hard to comprehend by outsiders. The same can be said about the statements describing music in the fragments from musical forums on http://forum.myspace.com: 
(1) Db major=Eb Dorian...if the bass stays in $E b$ and the players are soloing over Db....that would make the bass in Eb Dorian....unless the bassline is a clear cut certain mode...

(2) Grooving grapes, the last chord progression was funking sick!

(3) Find her doing 'Stompin at the Savoy'. Then tell me she hadn't worked years to master her axe.

(4) Nice setup. I dig the AOR music.

(5) i would say, that is totally up my alley. diggin your understated kicks and the simple catchiness of your voicing, arps, melodies, etc."

(6) Ben Webster - very important cat on sax!!!! Hot chicks too.

These examples show that professional Internet forums, on the one hand, contain a lot of musical terms like chord progression, mode, Dorian (mode), solo over, bassline, setup, Db major, Eb, AOR/Adult Oriented Rock etc. On the other hand, professional forums abound in professional jargonisms, as we see from the examples above: grooving (refers to playing music rhythmically), axe (stands for a musical instrument, and here voice as a musical instrument), to dig (to understand or to like something), kick (mistake), cat (musician, especially in jazz), chick (jazz and hip hop: young and pretty girl), and also clipped terms arp (arpeggio), and sax (saxophone).

Academic publications. Like professional Internet forums, academic publications represent the 'description/reflection' stage and the 'professional - professional' type of communication, as specialized literature on music is aimed at readers who are musically educated and have a good understanding of specific musical phenomena. However the main feature, which distinguishes academic musical discourse from other abovementioned genres and especially professional Internet forums, is a very high frequency of terminological units, and a general lack of musical jargonisms and professionalisms. Below are examples from two different academic sources - a musicological website, and a book on musicology:

(1) In Bach's countrapuntal practice some intervals have restricted treatment. Any such intervals are dissonant by definition. Intervals, such as P8, M3, M6 are relatively unrestricted, and are therefore, consonant. Others such as seconds, sevenths, tritones, and augmented intervals are dissonant, due to their restricted treatment. In keeping with this, the restrictions on parallel fifths and octaves make them dissonant. The same would be true for parallel seconds and sevenths. Open cadential fifths are dissonant in Bach's counterpoint; they are infrequent. Therefore, any rule of contrapuntal practice is a restriction that bestows dissonance (Solomon).

(2) "Scored for flute, clarinet, bassoon, viola, double bass (alternating with electric bass), synthesizer, and percussion 'Timberline' was Vierk's first major work to explore her sense of large-scale textural crescendo in an ensemble of diverse timbers. The opening pentatonic scales and small glissandos between scale notes in the viola give the piece a mildly Japanese flavor. Soon, one of the piece's most beautiful features begins: melodies of little thirty-second-note arabesques in the piano" (Gann 1997: 364).

The given extracts, relating to both classical music (example 1) and that of the twentieth century (example 2), contain a large number of terminological units, such as intervals and various types of intervals including P8, M3, M6, seconds, sevenths, tritones, fifths, 
octaves; counterpoint (contrapuntal), dissonance (dissonance); musical instruments (flute, clarinet, bassoon, viola, double bass, electric bass, synthesizer, percussion, piano); techniques of playing musical instruments (crescendo, glissando, arabesque), and scales (pentatonic scales).

Yet, jargonisms, although to a much lesser extent, can be found in academic papers, mostly in those describing subtleties related to jazz music. Thus, Mark Doffman in his article entitled 'Jammin' an Ending: Creativity, Knowledge, and Conduct among Jazz Musicians" (2011) uses instances of jazz jargon necessarily followed by explanations or definitions: in-head (initial playing of the melody prior to soloing), out-head (reiteration of the melody after the solos have been completed, swung (the rhytnmic feel in most jazz performances), straight eights (played in even quavers) etc. This deliberate preference of jargon over terminology in this case is justified by the author's intention to reproduce the exact words said by the musicians, participating in a recorded public jam session, in the short discussion before the improvisational performance, and later relate to them his musicological analysis.

Nonverbal language. Apart from verbal language, musical discourse is characterized by an intensive use of nonverbal elements, which can be conventionally divided into (1) graphic signs ('nonverbal terms') such as $\boldsymbol{f}$ or for loudness, or special signs for playing techniques (legato, staccato, cluster etc.); and (2) articulated signs such as physical gestures, modulations of sound, steady eye contact, facial expressions etc., which facilitate communication between musicians. A wide use of nonverbal signs allows not to waste time on lengthy explanations, while verbal interaction may ruin creative process. The current study considers only articulated signs that are directly involved in communication between musicians.

In his pedagogical study Kurkul (2007) lists three main categories of nonverbal interaction among musicians: kinesics (eye contact, facial expressions, hands gestures, body leaned forward while standing or sitting, head nodding), proxemics (physical distance between musicians, touching a part of a student's body), and paralanguage (silence and voice quality). The most frequent and fundamental means of nonverbal communication in musical discourse is eye contact and reciprocal visibility (Davidson \& Good 2002). It is typical of musicians to watch each other closely as they are improvising (Sawyer 2003: 45), as it allows musicians to be aware of each other and communicate, and to anticipate what will come next.

Different proportions of nonverbal elements also help differentiate genres within musical discourse. First of all, nonverbal language is peculiar to the professional professional level of communication, and jam sessions, belonging to the "creation of the musical product' stage, are typically characterized by a very high proportion of nonverbal elements. The photo from a Bossa Nova jam session, recorded at CBC Q studio (Q TV), illustrates the musicians' interaction at the moment a legendary pianist Paul Shaffer (to the left) points at the other musicians, Luanda Jones' band members, to conduct them to the end of improvisation (see Picture 1). 


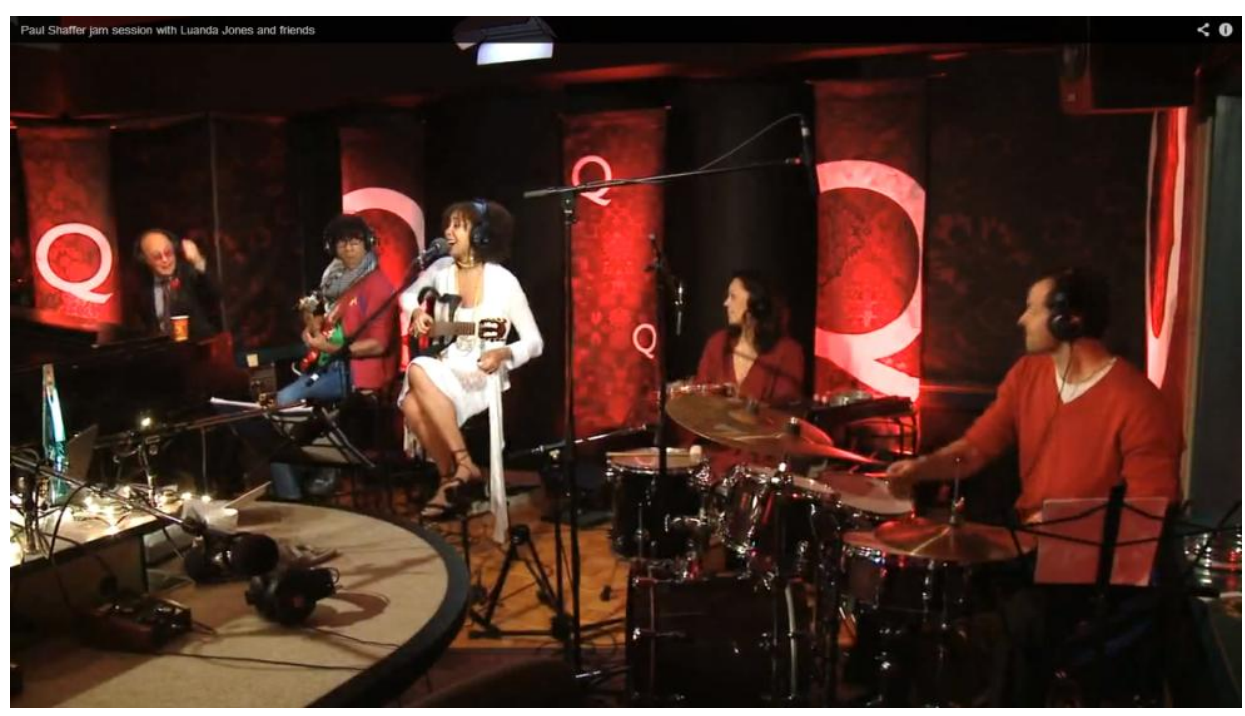

Picture 1: Nonverbal communication during improvisation

By rising from his seat and raising his hand, the pianist is trying to draw other participants' attention and engage with the band leader (guitar and vocals). Most gazes are directed at Luanda Jones (the guest band leader) and the pianist Paul Shaffer, who is taking on a role of a leader at this particular moment. The bassist is gazing at the band leader who carries the melody, as he is engaged in accompanying the groove and the vocalist/guitarist. The vocalist/guitarist, percussionist and drummer are gazing at the pianist who is taking charge of the ending. Doffman (2011) suggests present conduct and prior knowledge to be decisive in improvisational activity. So while the knowledge of chord sequences and tags is sufficient, the collaborative activity is focused on support and consolidation of the performance. However, when moving on to "the risker undertaking the end of the song", nonverbal interactions gain more intensity, and the degree of mutual gazing between musicians essentially increases.

The role of eye contact in jam sessions cannot be overestimated. If musicians cannot see each other, their coordination attempts will be in vain. Doffman (2011) describes disagreement between the pianist and the guitarist in an improvising group during a public jam session, when the guitarist has to use different ways of nonverbal, and in the end even verbal, interaction in order to conduct the pianist to the end of improvisation, as the latter seems to ignore his interlocutor's signs. The guitarist increasingly takes charge of the ending, trying to involve with the pianist by intensive gazing, then proxemic moves of his head and upper body towards the piano, and his raising of the guitar headstock. However the pianist's gaze is held "either resolutely down towards the keyboard or towards the bass or drums, but not towards the pianist". The guitarist is thus forced to draw the pianist's attention verbally, by calling out to him "Finish!", which is rather a necessary exception and indicates the "urgency in his closing of the song".

Live performances involve communication at two levels. Verbal communication is carried out at the professional - non-professional level, while nonverbal communication 
includes interaction at the professional - non-professional (nonverbal communication with audience, for example, raising the microphone in order to invite the audience to sing along), as well as professional - professional communication between band members, or between musicians and sound technicians. Upon the whole, the proportion of eye contact, body gestures and other articulated nonverbal signs at concerts is considerably lower than during jam sessions. On the other hand, live performances are more diverse in terms of ways of nonverbal communication, as they involve a lot of visual elements such as musicians' clothing, hairstyles, manners of walking/moving/playing instruments, numerous visual effects, lighting, videos shown at the background and so forth. From this perspective live performances (as well as other genres of musical discourse like music videos, articles in musical journals) provide opportunities of multidimensional and multidisciplinary analysis of how different modes (verbal language, music, sound, graphics, videos, photographs, eye contact, gestures, makeup etc.) work in harmony to produce certain meanings.

\section{Conclusion}

Musical discourse is a complex multi-perspective and multidimensional phenomenon, and the exploration of professional genres within musical discourse is a matter of integrating textual and contextual analysis, as the work of genre is to "mediate between social situations and the texts that respond strategically to the exigencies of those situations" (Swales 2009: 14). Semiosis, social context, social agents, social relations, and text in their diverse aspects in concert determine both text-internal and external features of musical discourse and act as reliable criteria in distinguishing between its genres. Semiosis is closely related to and directly depends upon the other components of musical discourse analysis. In this respect it is of particular linguistic interest, as it clearly illustrates how different social contexts correlate with different syntactic structures and how they invite different proportions of specialized and general language lexemes in certain genres of musical discourse.

Musical discourse as a many-sided phenomenon offers a great number of topics and ideas for further linguistic research, one of them being multimodal investigation of some of its genres. Modes of communication other than language are increasingly seen as relevant in social linguistic research (Bezemer \& Jewitt 2010). Therefore the study of language per se is extended to the study of language in combination with other resources, such as images, gesture, action, music and sound (O'Halloran 2011). Multimodal discourse analysis offers a promising direction of musical discourse research, as it opens up new possibilities to examine how multimodal resources "function intersemiotically" to mark and maintain identities.

\section{References}

Agawu, Kofi (2009). Music as discourse: Semiotic adventures in romantic music. Oxford, New York: Oxford University Press. 
Alim, H. Samy, Awad Ibrahim \& Alastair Pennycook (Eds.) (2009). Global linguistic flows: Hip hop cultures, youth identities, and the politics of language. New York, London: Routledge.

Baxter, Judith (2010). "Discourse analytic approaches to text and talk." In L. Litosseliti (Ed.), Research methods in Linguistics (117-137). London, New York: Continuum.

Becker, Howard (2000). "The etiquette of improvisation." Mind, culture, and activity, 7(3), 171-176.

Berliner, Paul (1994). Thinking in jazz: The infinite art of improvisation. Chicago, IL: University of Chicago Press.

Bezemer, Jeff \& Carey Jweitt (2010). Multimodal analysis: Key issues. In L. Litosseliti (Ed.), Research methods in Linguistics (180-197). London, New York: Continuum.

Bhatia, Vijay K. (1993). Analysing genre: Language use in professional settings. London: Longman.

Bhatia, Vijay K. (1997). "Introduction: Genre analysis and world Englishes." World Englishes, 16(3), 313-319.

Bhatia, Vijay K. (2004). Worlds of written discourse. London, New York: Continuum.

Bhatia, Vijay K. (2008). "Genre analysis, ESP and professional practice." English for specific purposes, 27(2), 161-174.

Blacking, John (1982). "The structure of musical discourse: The problem of the song text." Yearbook for traditional music, 14, 15-23.

Blommaert, Jan (2003). "Commentary: A sociolinguistics of globalization." Journal of sociolinguistics, 7(4), 607-623.

Bowker, Lynne \& Jennifer Pearson (2002). Working with specialized language: A practical guide to using corpora. London, New York: Routledge.

Bradby, Barbara (1990). "Do-talk and don't-talk: The division of the subject in girlgroup music." In S. Frith \& A. Goodwin (Eds.), On record: Rock, pop, and the written word (290-314). London, New York: Routledge.

Bradby, Barbara (2003). "Discourse analysis." In D. Horn, D. Laing, P. Oliver \& P. Wicke (Eds.), Continuum encyclopedia of popular music of the world (67-70). London, New York: Continuum.

Bullz-Eye (2006). "A Chat with Richard Hughes of Keane.” Retrieved 01.05.2013 from http://www.bullz-eye.com/music/interviews/2006/keane.htm.

Crystal, David (2003). English as a global language. Cambridge: Cambridge University Press.

Cutler, Cecelia (2007). "Hip hop language in sociolinguistics and beyond." Language and linguistics compass, 1(5), 519-538.

Davidson, Jane W. \& J.M. Good (2002). "Musical and social co-ordination between members of a string quartet: An exploratory study." Psychology of music, 30, 186201.

De Nora, Tia (2000). Music in everyday life. Cambridge: Cambridge University Press.

DeWall, C. Nathan, Richard S. Pond, Jr., W. Keith Campbell \& Jean M, Twenge (2011). "Tuning in to psychological change: Linguistic markers of psychological traits and emotions over time in popular U.S. song lyrics." Psychology of aesthetics, creativity, and the Arts, 5(3), 200-207.

Doffman, Mark (2011). 'Jammin' an ending: Creativity, knowledge, and conduct among jazz musicians.” Twentieth-century music, 8(2), 203-225. 
Dunyasheva, Lilia (2010). "Reflection of gender stereotypes in the song lyrics discourse of Disney animation." Vestnik Nizhny Novgorod Linguistic University, 11, 54-63.

Fairclough, Norman (2003). Analysing discourse: Textual analysis for social research. London: Routledge.

Fairclough, Norman (2006). Language and globalization. London: Routledge.

Gann, Kyle (1997). American music in the twentieth century. New York: Schirmer Books.

Gunnarsson, Britt-Louise (2009). Professional discourse. London, New York: Continuum.

Hitchcock, H. Wiley \& Stanley Sadie (Eds.) (2002). New Grove dictionary of American music. 4 vols. New York: Oxford University Press.

Hoban, Alex (2013). "Various artists - 'Grime 2.0'." NME reviews. Retrieved 13.05.2013 from http://www.nme.com/reviews/various-artists/14410.

Ibrahim, Awad El Karim M. (1999). "Becoming Black: Rap and hip hop, race, gender, identity, and the politics of ESL learning." TESOL Quarterly, 33(3), 349-369.

Interview Magazine. Postmodern love: Charlotte Kemp Muhl and Sean Lennon. Retrieved 01.05.2013 from http://www.interviewmagazine.com/music/goast-of-asaber-tooth-tiger-charlotte-kemp-muhl-sean-lennon\#

Kernfeld, Barry (2003). New Grove dictionary of jazz. 2nd edition. New York: Oxford University Press.

Kreyer, Rolf \& Joybrato Mukherjee (2009). "The style of pop song lyrics: A corpuslinguistic pilot study." Anglia-Zeitschrift fur englische Philologie, 125(1), 31-58.

Kurkul, Wen W. (2007). "Nonverbal communication in one-to-one music performance instruction." Psychology of music, 35(2), 327-362.

Latham, Alison (2002). Oxford companion to music. New York: Oxford University Press.

Mackay, Emily (2013). "Beyoncé. The O2, London, Monday, April 29." NME reviews. Retrieved 31.05.2013 from http://www.nme.com/reviews/beyonce/14407.

Moore, Allan F. (2001). "Categorical conventions in music discourse: Style and genre." Music \& letters, 82(3), 209-223.

Morgan, Robert P. (1982). "Theory, analysis, and criticism." Journal of musicology, 1(1), 15-18.

Mudryan, N.S. (2011). "Theoretical and methodological basis for analyzing the discourse of music." Vestnik of Kharkov National University n.a. V.N. Karazin, 941, 89-92.

Murphy, Tim (1990). "The song stuck in my head phenomenon: A melodic din in the lad." System, 18(1), 53-64.

Murphey, Tim (1992). "The discourse of pop songs.” TESOL Quarterly, 26(4), 770-774.

O'Halloran, Kay L. (2011). "Multimodal discourse analysis." In K. Hyland \& B. Paltridge (Eds.), Continuum companion to discourse analysis (120-137). London and New York: Continuum.

Pavlovová, Milada (2013). Complex linguistic analysis of musical discourse: The genre of concert notice. Saarbrücken: LAP.

Pennycook, Alastair (2010). "Popular cultures, popular languages, and global identities." In N. Coupland (Ed.), The handbook of language and globalization (592-607). Oxford: Blackwell Publishing. 
Pettijohn, Terry F. \& Donald F. Sacco, jr. (2009). "The language of lyrics: An analysis of popular Billboard songs across conditions of social and economic threat." Journal of Language and Social Psychology, 28(3), 297-311.

Roy, William G. (2010). Reds, whites and blues: Social movements, folk music, and race in the United States. Princeton: Princeton University Press.

Sawyer, R. Keith (2003). Group creativity: Music, theater, collaboration. Mahwah, NJ \& London: Lawrence Erlbaum.

Sawyer, R. Keith (2005). Music and conversation. In D. Meill, R. MacDonald \& D.J. Hargreaves (Eds.), Musical communication (45-60). Oxford, New York: Oxford University Press.

Skrebnev, Y.M. (1994). Fundamentals of English stylistics. Moscow: Vysshaya Shkola.

Solomon, Larry J. Consonance and dissonance. Music theory and analysis. Solomon's music resources. Retrieved 12.03.2013 from: http://www.solomonsmusic.net/consonance.htm.

Swales, John M. (2009). "Worlds of genre - metaphors of genre.” In C. Bazerman, A. Bonini \& D. Figueiredo (Eds.), Genre in a changing world (1-16). Fort Collins, Colorado: The WAC Clearing House.

Tagg, Fhilip (2003). Analyzing popular music: Theory, method and practice. Cambridge, New York: Cambridge University Press.

Terkourafi, Marina (Ed.) (2010). Languages of global hip hop. London, New York: Continuum.

Q TV. Q Friday live: Paul Shaffer jam session with Luanda Jones and friends. Retrieved 01.06.2013 from http://www.youtube.com/watch? $=0 \mathrm{oQX} 8 \mathrm{iBYKxNs.}$

Walser, Robert (1993). Running with the devil: Power, gender and madness in heavy metal music. Hanover, NH: Wesleyan University Press.

Welch, Andy (2013). "Charlie Boyer and the Voyeurs - 'Clarietta'." NME reviews. Retrieved 17.05.2013 from http://www.nme.com/reviews/charlie-boyer-and-thevoyeurs/14426.

\section{About the author}

Evgeniya Aleshinskaya is Candidate of Philological Sciences, Assistant Professor, State University of Nizhniy Novgorod named after N.I. Lobachevsky in Russia. She teaches graduate courses in English as a Second (Foreign) Language, English for Special Purposes, translation, and English stylistics. For ten years she has researched aspects of contemporary musical terminology, focusing on its semantics, onomasiology, cognitive peculiarities, and use in and beyond musical discourse. Her current research projects investigate various genres of musical discourse, as well as style and linguistic hybridity in globalized musical discourse. 